\title{
Estimating reservoir geomechanical parameters for enhanced reservoir characterization: case study of "Tobi" field, Niger Delta
}

\author{
Sunday J. Olotu ${ }^{1}$ - Olatunbosun A. Alao ${ }^{1}$ Paul G. Agbai ${ }^{1}$ - Olaolu Afolabi ${ }^{1}$ - Esther B. Inaolaji ${ }^{1}$
}

Received: 6 April 2020 / Accepted: 8 July 2020 / Published online: 25 July 2020

(c) Springer Nature Switzerland AG 2020

\begin{abstract}
Reservoir geomechanical parameters in "Tobi" Field, Niger Delta were estimated using well log data with the intention of improving reservoir characterization and establishing stress regime of the field. A suite of well log data were interpreted, reservoirs were identified and correlated across three (3) wells and their geomechanical parameters computed from empirical relations. Three (3) reservoir units were delineated from these wells that falls within the hydrocarbon windows (Agbada Formation). We estimated several geomechanical parameters, which include, but is not limited to, Young's modulus, Poisson's ratio, bulk compressibility, unconfined compressive strength (UCS), shear modulus, heat production, vertical stress (overburden), minimum horizontal stress, maximum horizontal stress, shear stress normal to fault plane, shear stress in direction of dip, and shear stress in direction of strike. The bivariate crossplots of heat production and Young's modulus indicated that the amount of heat produced by the shaly materials affects the elastic properties of the reservoir units and flow rate. The crossplots of Poisson's ratio versus compressional velocity are expressly well-defined and exponentially decaying with the compressional velocity, indicating an inverse relationship between the two (2) parameters. For stress tensor analysis, the study confirmed the defining condition of $S_{v}>S_{H \max }>S_{h m i n}$ as normal fault, which is fault regime prevalent in the study area, in line with Andersen's classification. Rotation of principal stresses on fault plane showed negative shear stress in strike direction. This research concluded that geomechanical parameters of hydrocarbon reservoirs in "Tobi" field are diagnostic in reservoir characterization and in establishing the type of faults in reservoirs.
\end{abstract}

Keywords Geomechanical parameters · Reservoir · Young's modulus · Poisson's ratio · Stress · Tensor

\section{Introduction}

Geomechanics deals with the study of processes of deformation in soils and rocks, leading to failure due to variations in stress, pressure, temperature as well as other environmental factors [1]. Application of geomechanics leads to reduction of risks and optimization of rewards associated with the mechanical failure of the reservoirs/ formations due to hydrocarbon exploration and production activities. Such activities include but is not limited to drilling of oil and gas wells, water/gas flooding, hydraulic fracturing, and depletion. Failure of a geological formation in the crust (subsurface) occurs when the stresses it is subjected to surpass its strength. Stresses are produced in the subsurface by various geological evolution and transformation factors such as deposition (gravitational loading), uplift, tectonics, stress relaxation, pressure inflation or deflation and thermal effects [2]. This indicates that stresses in the subsurface are always changing with time and cannot be extrapolated to everywhere at any given time. Assessment of reservoir geomechanical begins with estimating the strengths, stresses, and pressure profiles of the formations. Therefore, the role of geomechanics is to forecast when failure of geological formation would

Sunday J. Olotu, jephotto@gmail.com | 'Obafemi Awolowo University, Ile-Ife, Nigeria. 
happen, evaluate its risks and opportunities, and recommend mitigation plan(s). Also, good understanding of geological history of the reservoir of interest is vital to the development of reliable geomechanical model [2].

The longevity of reservoir lifespan is affected by reservoir field stress levels and operational activities such as production and injection which cause rigorous field development and production difficulties, such as fault reactivation, water break through, breaches in cap rock integrity, changes in permeability, compaction and subsidence, thereby making the reservoir a geomechanical stress challenging environment [3]. Virtually all producing fields have these geomechanical stress-related problems which need to be properly managed. Development and production issues of any reservoir could be huge geomechanical problems, because hydrocarbon reservoirs suffer an initial preproduction stress state due to weakness or weak spot of the formation leading to rock failure [4]. Another reason is due to large pressure drop of sand units during production lifetime as it has thick reservoir net pay interval of unconsolidated formation, high porosity, high pressure and high temperature, detrimentally affecting the reservoirs $[5,6]$.

Zoback [7] further reiterated that detailed geomechanical analysis of reservoir provides the foundation for addressing the plethora of problems found from the onset of exploration throughout the lifespan of hydrocarbon reservoirs. Based on this, geomechanics has been acknowledged in the exploration and production industry as a major innovative and contributing skilled discipline for understanding reservoir mechanical behavior in conventional and unconventional assets. Geomechanics has displayed proven role from quantifying drilling problems of exploration wells to optimizing recovery of complicated hydrocarbon reserves in marginal or mature reservoirs. Thus, geomechanical analysis and modeling are tools employed to generate data for the design of a stable wellbore, which will assuredly save costs, avoid problems and reduce risks associated with the commercial production.

This research set out to identify the lithology and delineate hydrocarbon reservoir units within the wells, compute petrophysical parameters and estimate geomechanical parameters of the delineated hydrocarbon reservoirs with a view to enhancing reservoir characterization.

\subsection{Location and geology of the study area}

"Tobi" Field is an onshore field located within the Tertiary sedimentary fills (deposits) of the Niger Delta Basin, which is between longitudes $3^{\circ} \mathrm{E}$ and $9^{\circ} \mathrm{E}$ and latitudes $4^{\circ} \mathrm{N}$ and $6^{\circ} \mathrm{N}$ (Fig. 1). The Niger Delta is situated in the southern part of Nigeria, bounded by the Gulf of Guinea in the south and by older Cretaceous elements like the Anambra Basin,
Abakaliki Uplift and Afikpo Syncline in the north. The Niger Delta comprises of three (3) formations in its lithostratigraphic sequence, which are: Akata, Agbada and Benin Formations $[8,9]$. Hydrocarbon accumulation is found within the unconsolidated to semi-consolidated sands of the Agbada Formation of Niger Delta Basin, aided by both structural and stratigraphic traps. The sand reservoir is either hydrocarbon-bearing or water-bearing. Growth faults and rollover anticlines are the two structural styles in the Niger Delta. The interplay between rates of sediment supply and subsidence have controlled the structure and stratigraphy of the delta throughout its geologic history. Important effects on the rate of sedimentation have been climatic variations and eustatic sea-level changes in the hinterland. Differential sediment loading of unstable shale and initial basement morphology has controlled subsidence in the region [9].

\section{Materials and method}

A suite of well logs comprising of gamma ray, resistivity, neutron, density, and sonic logs for three (3) wells, A, B, and $C$, was obtained from Shell Petroleum Development Company of Nigeria Limited (SPDC) through the Department of Petroleum Resource (DPR), Nigeria. Of all the listed logs, neutron log was not available for only well $A$. The log dataset was quality checked and loaded into three (3) softwares [Petrel, GeolOil and Strater 5] for conventional seismic and log interpretations. The Petrel software used was provided by Schlumberger to the Department of Geology, Obafemi Awolowo University, lle-Ife, Nigeria. A summarized chart of the research workflow is given in Fig. 2, which indicated that the estimation of petrophysical parameters (for example, volume of shale as well as volume of clay) and several geomechanical parameters (such as Poisson's ratio, Young's modulus, shear modulus, bulk compressibility, sand production index [SPI], unconfined compressive strength [UCS], shear stress, heat production, vertical stress, maximum horizontal stress, minimum horizontal stress, stress normal to the fault plane, shear stresses in directions of strike and dip).

\subsection{Reservoir geomechanical analysis}

Mechanical properties of rocks include elastic and inelastic properties. For this research, the elastic properties estimated include elastic modulus (E), Poisson's ratio (v), rigidity/shear modulus $(G)$, bulk modulus $\left(K_{b}\right)$, bulk compressibility $\left(C_{b}\right)$, and sand production prediction index (SPI). The inelastic properties include unconfined compressive strength (UCS), shear stress $(\tau)$, vertical stress $\left(S_{v}\right)$, horizontal stresses $\left(\mathrm{S}_{\mathrm{Hmax}}\right.$ and $\left.\mathrm{S}_{\mathrm{hmin}}\right)$ and heat production 


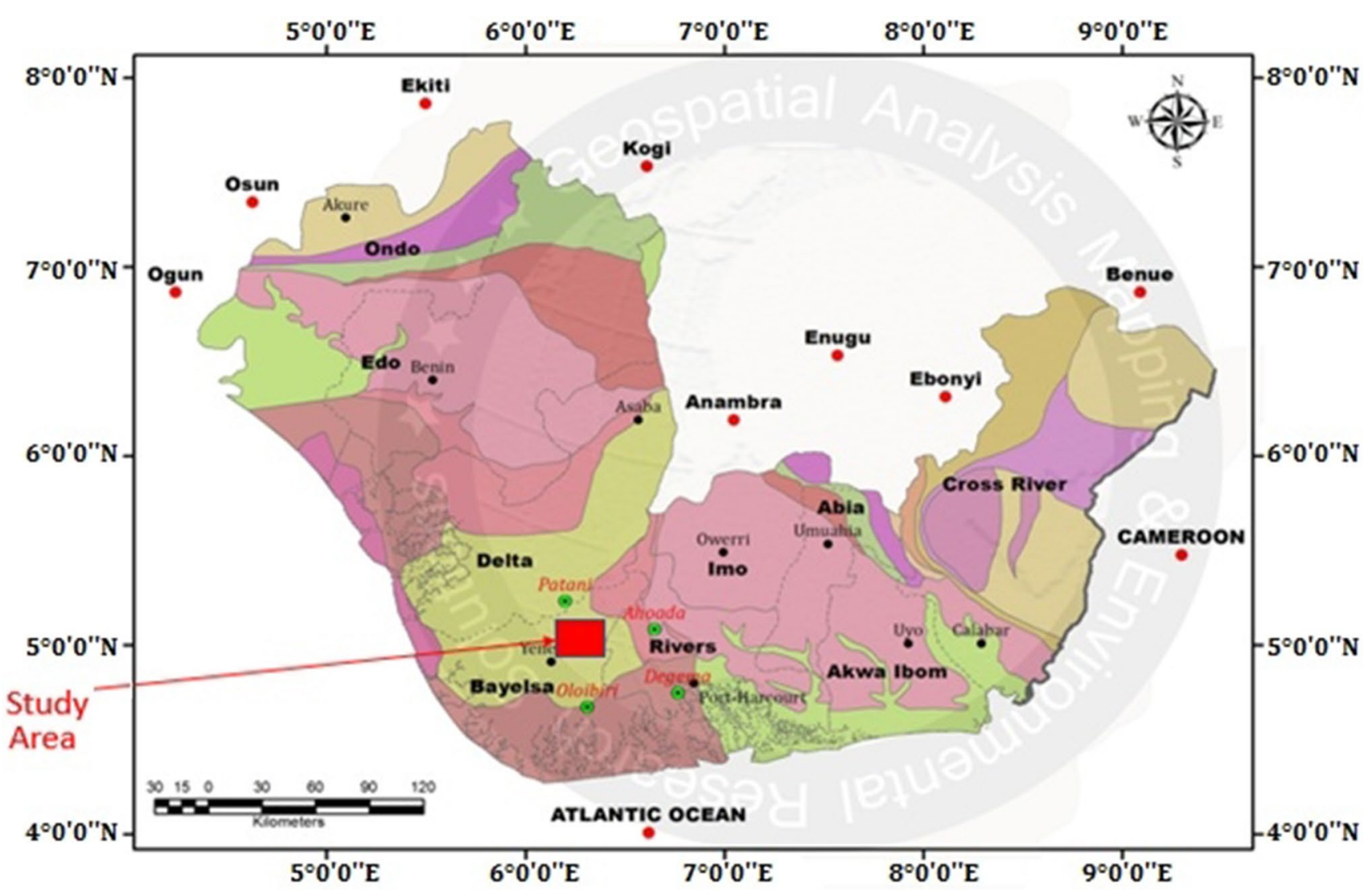

Fig. 1 Map showing Niger delta and location of the "Tobi" field

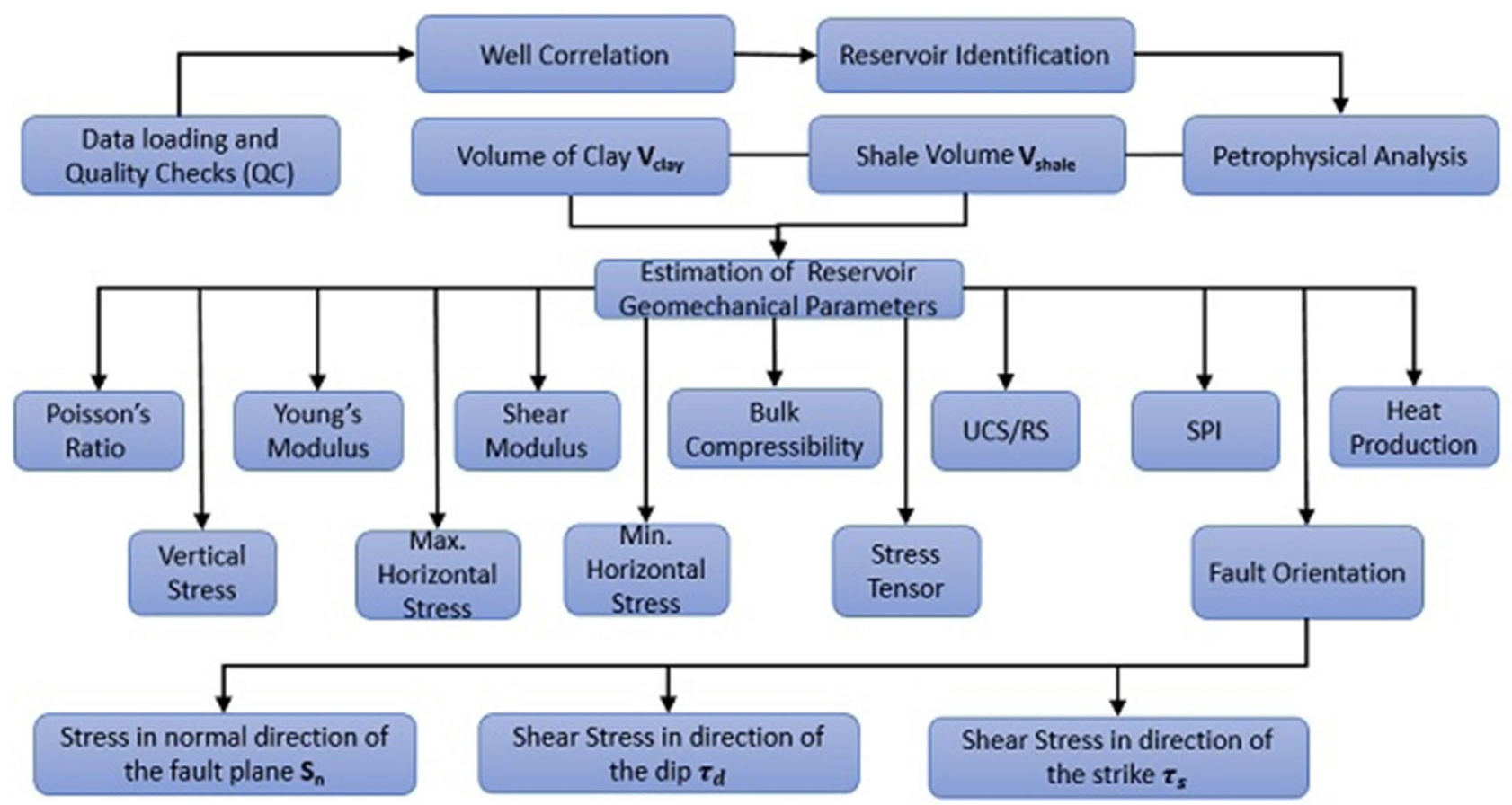

Fig. 2 Summarized chart of the workflow adopted for this research 
$\left(A_{o}\right)$. All these mechanical properties were estimated using density log, gamma ray log and sonic logs (compressional and shear transit times) as described in previous works [10-12].

Poisson's ratio and Young's modulus were determined from $\mathrm{P}$ - and S-wave velocity while bulk modulus $\left(\mathrm{K}_{\mathrm{b}}\right)$, shear modulus $(G)$, and bulk compressibility $\left(C_{b}\right)$ were obtained from wireline logs using empirical relationships as described in past research outcomes [13-15].

Interval transit time of the shear wave $\left(\Delta \mathrm{T}_{\mathrm{S}}\right)$ was estimated and used to obtain the shear wave velocity $\left(V_{s}\right)$ where shear transit times data were not available. This was achieved using the Greenberge and Castagna [16] relationships in Eqs. (1), (2), and (3) below:

$\mathrm{V}_{\mathrm{p}}=\frac{304878}{\Delta \mathrm{T}_{\mathrm{c}}}$

$\mathrm{V}_{\mathrm{p}}=\frac{304878}{\Delta \mathrm{T}_{\mathrm{s}}}$

$\mathrm{V}_{\mathrm{s}}=\left(0.804 \times \mathrm{V}_{\mathrm{p}}\right)-0.856$

where $V_{p}$ is compressional wave velocity, $V_{s}$ is shear wave velocity, $\Delta \mathrm{T}_{s}$ is shear wave transit time in $\mu \mathrm{sec} / \mathrm{ft}$, and $\Delta \mathrm{T}_{\mathrm{c}}$ is sonic compressional time in $\mu \mathrm{sec} / \mathrm{ft}$.

\subsection{Poisson's ratio (u)}

Poisson's ratio is the rate of change of lateral strain to the longitudinal strain. It is dimensionless and describes the material's potential to vary in shape and/or volume during deformation [17]. This was computed using the Anderson's method (Eq. 4) expressed as:

$v=0.125 \times \mathrm{V}_{\mathrm{sh}}+0.27$

where $\mathrm{U}$ is Poisson's ratio (dimensionless) and $\mathrm{V}_{\mathrm{sh}}$ is volume of shale.

\subsection{Shear modulus (G)}

Shear modulus is the applied stress divided by shear strain [7]. It is a material's resistance to shear deformation. This was estimated from this formula:

$\mathrm{G}=\frac{\mathrm{KS} 5 \times \text { density }}{\Delta \mathrm{T}_{\mathrm{s}}^{2}}$

where $\mathrm{G}$ is shear modulus in psi or $\mathrm{MPa}$ and $\Delta \mathrm{T}_{\mathrm{S}}$ is shear wave transit time in $\mu \mathrm{sec} / \mathrm{ft}$.

For rocks with porosity, KS5 equal to 13,400 and the density refers to the bulk density of the formation.

\subsection{Bulk modulus $\left(K_{b}\right)$}

Bulk modulus is defined as the hydrostatic pressure divided by volumetric strain. It is a material's resistance against compression [1]. Also, it signifies the stiffness in hydrostatic compression. Bulk modulus with porosity was determined by the relationship in Eq. (6) below:

$\mathrm{K}_{\mathrm{b}}=K S 5 \times$ density $\times \frac{1}{\Delta \mathrm{T}_{c}^{2}}-\frac{4}{3} \times \frac{1}{\Delta \mathrm{T}_{s}^{2}}$

where $K_{b}$ is bulk modulus in psi and for rocks with porosity, KS5 equal to 13,400 .

Also, $\Delta \mathrm{T}_{\mathrm{S}}$ is shear wave transit time in $\mu \mathrm{sec} / \mathrm{ft}$ and $\Delta \mathrm{T}_{\mathrm{C}}$ is sonic compressional time in $\mu \mathrm{sec} / \mathrm{ft}$.

The density referred to in the Eq. (6) above is the bulk density, $\rho_{b}$ in $\mathrm{g} / \mathrm{cm}^{3}$ [18].

\subsection{Bulk compressibility $\left(C_{b}\right)$}

Bulk compressibility is the inverse of bulk modulus, which was determined from the relationship in Eq. (7) below [7]:

$C_{b}=1 / K_{b}$

where $\mathrm{K}_{\mathrm{b}}$ is bulk modulus in psi or Mpa and $\mathrm{C}_{\mathrm{b}}$ is bulk compressibility in $\mathrm{psi}^{-1}$.

\subsection{Young's modulus (E)}

Young's modulus or modulus of elasticity is applied uniaxial stress divided by normal strain. It was determined from shear modulus and Poisson's ratio as in Eq. (8) below [7]:

$E=2 \times G \times(1+v)$

where $\mathrm{G}$ is shear modulus in psi and $\mathrm{v}$ is Poisson's ratio (dimensionless).

\subsection{Rock strength/unconfined compressive strength (UCS)}

Rock strength or the unconfined compressional strength measured in psi is given by Zoback [7] as:

$\mathrm{UCS}=(3+4.1 \times \mathrm{E}) \times 145$

where $\mathrm{E}$ is Young's modulus in psi.

\subsection{Prediction of sand production index (SPI)}

Sand production is a major concern in petroleum industry because of severe difficulties and the related operational and technical challenges. Predicting sand production onset 
permits operators to successfully manage the oil recovery procedure in the most technical and cost-effective manner. The prediction entails precise data and calculations to ensure the field critical pressure to determine sanding; and the rock elastic properties is the most important factor, which can be obtained from well logs such as acoustic and density logs.

Sanding evaluation was done using Schlumberger Sand Production Index (SPI). Sand production will occur if SPI is less than $5.9 \times 10^{7} \mathrm{Mpa}$ [3]. The equation that relates sanding to the dynamic elastic moduli is given as:

$\mathrm{SPI}=\mathrm{K}_{\mathrm{b}} \times \mathrm{G}=\frac{E}{3 \times(1-\mu)} \times \frac{E}{2 \times(1+\mu)}$

where $\mathrm{K}_{\mathrm{b}}$ is bulk modulus in psi, $\mathrm{G}$ is shear modulus in psi or $\mathrm{MPa}, \mathrm{E}$ is Young's modulus in psi or $\mathrm{Mpa}$, and $\mu$ is shear modulus in psi or MPa.

\subsection{Heat production $\left(A_{0}\right)$}

Heat is generated in rocks principally through the radioactive decay of unstable isotopes that release energy in the form of alpha particles $\alpha$, beta particles $\beta$, gamma radiation $\gamma$, neutrinos $\eta$ and anti-neutrinos $\ddot{\ddot{u}}$. The rate of radiogenic heat generation within rocks is related to the: (i) quantity of radioactive materials, (ii) rate of decay and (iii) energy of the emitted particles.

Heat production in wells reflects the amount of radioactive substances present in the well and can be used to correlate the shalines of a reservoir rock in an oil well. Various models have been proposed but the most reliable is the one proposed by Bucker and Ryback [19] given by the Eq. (11) below:

$A_{o}=m(R H O B \times G R)$

where $m$ equal to 0.005 the gradient of heat production graph, $\mathrm{RHOB}$ is the density log in $\mathrm{kg} / \mathrm{m}^{3}$, GR is the gamma ray log in API, and the unit of heat production is $\mu \mathrm{W} / \mathrm{m}^{3}$.

\subsection{Determination of magnitudes of in situ stresses}

\subsubsection{Vertical stress}

Vertical Stress $\left(\mathrm{S}_{\mathrm{v}}\right)$ is one of the three principal stresses and was determined by integrating the density $\left(\rho_{b}\right)$ of the materials from surface to the depth of interest as in Eq. (12) below [20]:

$$
\boldsymbol{S}_{v}=\int^{z} \rho_{\mathrm{b}}(z) g d z
$$

\subsubsection{Maximum horizontal stress}

Maximum horizontal stress, $\mathrm{S}_{\mathrm{Hmax}}$, which is second of the three principal stresses, is calculated using Eq. (13) below [21]:

$\mathrm{S}_{\mathrm{H} \max }=\boldsymbol{S}_{\mathrm{v}} \frac{v}{1-v}$

where $v$ is the Poisson's ratio (dimensionless), $S_{v}$ is the vertical stress in psi, $\rho_{b}$ is the bulk density in $\mathrm{g} / \mathrm{cm}^{3}, d_{z}$ is the depth in $\mathrm{ft}, \mathrm{g}$ is the acceleration due to gravity which is $9.8 \mathrm{~m} / \mathrm{s}^{2}$ and the unit of $\mathrm{S}_{\mathrm{Hmax}}$ is psi.

\subsubsection{Minimum horizontal stress}

Minimum horizontal stress $\left(\mathrm{S}_{\mathrm{hmin}}\right)$ is last of the three principal stresses which could be technically measured and/or calculated. Both the magnitude and direction of minimum horizontal stress are needed for accomplishing borehole stability during directional drilling, hydraulic fracturing carried out purposely to enhance oil production, estimation of wellbore failure and/or sand production, and used in selective perforation to avert collapse or sanding during oil production. Minimum horizontal stress is estimated in the Eq. (14) below [21]:

$\mathbf{S}_{\mathrm{hmin}}=\rho_{b}+v \times \mathbf{S}_{\mathrm{v}}$

where $\rho_{b}$ is bulk density, $\mathrm{U}$ is Poisson's ratio, $\mathbf{S}_{\mathbf{v}}$ is vertical stress in psi and the unit of $\mathbf{S}_{\mathbf{h m i n}}$ is psi.

\subsubsection{Stress tensor}

A tensor is an array of mathematical objects (usually numbers or fractions) which transforms according to certain rules under coordinate changes [22]. Stress is a tensor which can be fully defined by a point within the rock mass with magnitudes and direction of three orthogonal principal stresses; maximum horizontal stress $\left(\mathbf{S}_{\mathrm{Hmax}}\right)$, minimum horizontal stress $\left(\mathbf{S}_{\mathbf{h m i n}}\right)$ and vertical stress $\left(\mathbf{S}_{\mathbf{v}}\right)$, which is the overburden. Stress is a rank-2 tensor having nine components, as shown below:

$\mathbf{S}=\left[\begin{array}{lll}S_{11} & S_{12} & S_{13} \\ S_{21} & S_{22} & S_{23} \\ S_{31} & S_{32} & S_{33}\end{array}\right]$

The stress tensor $\mathbf{S}$ that is used in this research is called Cauchy Stress which really depends on the choice of coordinate system. For Cauchy stress, due to principle of conservation of angular momentum, the off-diagonal components are symmetric; that is, $\boldsymbol{S}_{12}=\boldsymbol{S}_{21}, \boldsymbol{S}_{13}=\boldsymbol{S}_{31}$ 
and $\boldsymbol{S}_{32}=\boldsymbol{S}_{23}$. Therefore, the Cauchy stress can be reduced to have only six unique components [7]:

$\mathbf{S}=\left[\begin{array}{lll}S_{11} & S_{12} & S_{13} \\ & S_{22} & S_{23} \\ & & S_{33}\end{array}\right]$

It turns out that there is a particular coordinate system that will diagonalize the stress tensor, that is, there are no shear stresses. Thus, only normal stresses will be acting on the body. That particular choice of coordinate system is called the Principle Direction and they are the eigenvalues of the stress tensor $\mathbf{S}$. What is left when you use those eigenvalues to diagonalize the stress tensor is $\mathbf{S}^{\prime}$ according to the Eq. (18) below [7]:

$\mathbf{S}^{\prime}=\mathbf{Q}^{-1} \mathbf{S Q}=\mathbf{Q}^{\mathbf{T}} \mathbf{S Q}=\mathbf{S}_{\mathbf{G}}$

where $\mathbf{Q}$ is the matrix of the eigenvectors, $\mathbf{Q}^{\mathbf{T}}$ is the transposed matrix of the eigenvector, and $\mathbf{S}_{\mathbf{G}}$ is the stress tensor in geographical coordinate.

Equation (17) is true if and only if $\mathbf{Q}$ is unitary or orthonormal, that is, the eigenvectors must be unit vectors.

$\mathbf{Q}=\left[\overrightarrow{\mathbf{v}_{1}}: \overrightarrow{\mathbf{v}_{2}}: \overrightarrow{\mathbf{v}_{3}}\right]$

where $\overrightarrow{\mathbf{v}}_{\boldsymbol{i}}$ are eigenvectors. Hence,

$\mathbf{S}^{\prime}=\left[\begin{array}{ccc}\mathrm{S}_{1} & 0 & 0 \\ 0 & \mathrm{~S}_{2} & 0 \\ 0 & 0 & \mathrm{~S}_{3}\end{array}\right]$

with $\mathbf{S}_{1}>\mathbf{S}_{\mathbf{2}}>\mathbf{S}_{\mathbf{3}} \equiv \mathbf{S}_{\mathrm{v}}>\mathbf{S}_{\mathrm{Hmax}}>\mathbf{S}_{\mathrm{hmin}}$, which are the principal stresses.

If the maximum and minimum changes of stress at the wall of the borehole exceeds the strength of the rock (such as the UCS), breakout along the wellbore may happen along the direction of minimum horizontal stress [7].

\subsubsection{Fault orientation}

The orientation of fault is determined by the use of the three principal stresses, that is, the eigenvalues and the unit vectors in the specified direction. The principal stresses are rotated in the geographical coordinate system and then rotated on the fault because attitude of the fault is in geographical coordinate system. The orientation of fault involves the determination of fault traction $\vec{\tau}$, stress in the normal direction of the fault plane $\mathbf{S}_{n}$, shear stress in the direction of the dip $\tau_{d}$ and shear stress in the direction of the strike $\tau_{s}$ [7].

$$
\begin{aligned}
& \mathbf{S}_{\mathbf{G}}=\left[\begin{array}{ccc}
\mathrm{S}_{\mathrm{v}} & 0 & 0 \\
0 & \mathrm{~S}_{\text {Hmax }} & 0 \\
0 & 0 & \mathrm{~S}_{\mathrm{hmin}}
\end{array}\right] \\
& \hat{n}=\left[\begin{array}{c}
-\sin (\text { strike }) \sin (\text { dip }) \\
\cos (\text { strike)sin(dip) } \\
-\cos (\text { dip })
\end{array}\right] \\
& \hat{n}_{\boldsymbol{d}}=\left[\begin{array}{c}
-\sin (\text { strike }) \cos (\text { dip }) \\
\cos (\text { strike) } \cos (\text { dip }) \\
\sin (\text { dip })
\end{array}\right] \\
& \hat{n}_{\mathbf{s}}=\left[\begin{array}{c}
\cos (\text { strike }) \\
\sin (\text { strike }) \\
0
\end{array}\right] \\
& \mathbf{S}_{\boldsymbol{n}}=\vec{\tau} \cdot \hat{n} \\
& \boldsymbol{\tau}_{\boldsymbol{d}}=\vec{\tau} \cdot \hat{n}_{\boldsymbol{d}} \\
& \boldsymbol{\tau}_{\boldsymbol{s}}=\vec{\tau} \cdot \hat{n}_{\boldsymbol{s}} \\
& \vec{\tau}=\mathbf{S}_{G} \cdot \hat{n}
\end{aligned}
$$

where $\mathbf{S}_{\mathbf{G}}$ is the stress tensor in geographical coordinate, $\hat{n}$ is unit vector normal to fault plane, $\hat{n}_{\boldsymbol{d}}$ is unit vector in direction of dip, and $\hat{n}_{s}$ is unit vector in direction of strike.

\subsubsection{Well log interpretation}

Identification of hydrocarbon reservoir sands was accomplished by studying the log signatures of both gamma ray and resistivity logs. Using Petrel software, neutron-density crossplots were done to determine gas saturated, waterbearing and hydrocarbon-bearing sands.

\section{Results and discussion}

With the correlation of all available wells, as depicted in Fig. 3, three reservoir sands (Sand 1, Sand 2 and Sand 3) and their lateral continuities were determined by picking formation tops, which falls within the hydrocarbon windows (Agbada Formation). Table 1 shows the thickness of each of the reservoir sands delineated across wells and depth which ranges between 255 to $484 \mathrm{ft}$, while Fig. 4 shows the location of the three (3) wells, labelled A, B and $C$, in the study area. In these wells $A, B$, and $C$, the reservoir sands range in depth from $8,380.5-9,912.5 \mathrm{ft}$, $8,398.0-9,940.5 \mathrm{ft}$ and 8,378.5-9,982.5 ft respectively. 


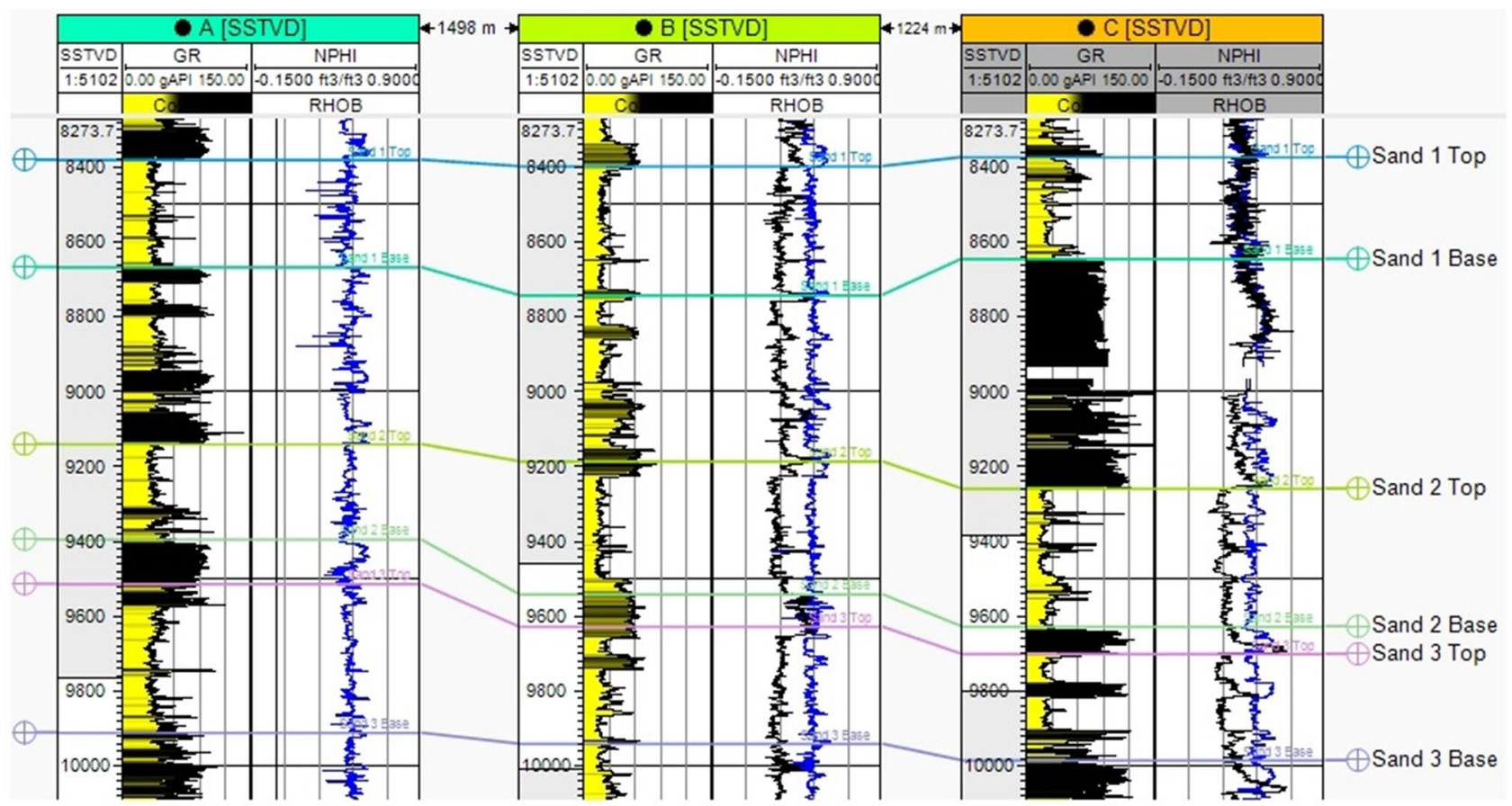

Fig. 3 Well correlation of the identified reservoir sands and their lateral continuity (Produced with Petrel Software, Version 2015)

Table 1 Hydrocarbon reservoir thicknesses across wells A, B and C

\begin{tabular}{|c|c|c|c|c|c|c|c|c|c|}
\hline \multirow[t]{2}{*}{ Well } & \multicolumn{3}{|l|}{ Reservoir 1} & \multicolumn{3}{|l|}{ Reservoir 2} & \multicolumn{3}{|l|}{ Reservoir 3} \\
\hline & $\begin{array}{l}\text { Sand } 1 \text { Top } \\
\text { (ft) }\end{array}$ & $\begin{array}{l}\text { Sand } 1 \text { Base } \\
\text { (ft) }\end{array}$ & Thickness (ft) & $\begin{array}{l}\text { Sand } 2 \text { Top } \\
\text { (ft) }\end{array}$ & $\begin{array}{l}\text { Sand } 2 \text { Base } \\
(\mathrm{ft})\end{array}$ & Thickness (ft) & $\begin{array}{l}\text { Sand } 3 \text { Top } \\
\text { (ft) }\end{array}$ & $\begin{array}{l}\text { Sand } 3 \text { Base } \\
\text { (ft) }\end{array}$ & Thickness (ft) \\
\hline A & 8380.5 & 8667.5 & 287.0 & 9139.5 & 9394.5 & 255.0 & 9513.5 & 9997.5 & 484.0 \\
\hline B & 8398.0 & 8743.0 & 345.0 & 9189.0 & 9541.0 & 352.0 & 9628.0 & $10,013.5$ & 385.5 \\
\hline C & 8373.6 & 8645.8 & 272.2 & 9249.3 & 9527.7 & 278.4 & 9701.0 & $10,052.0$ & 351.0 \\
\hline
\end{tabular}

\subsection{Sanding}

Bulk compressibility predicts sanding (sand production). Higher water cuts result in higher prospect of sanding due to adhesion of water on surface of sand grains. The threshold beyond which sanding may occur corresponds to $C_{b}$ equal to $0.75 \times 10^{-6} \mathrm{psi}^{-1}$. As shown in Table 2 , bulk compressibility for oil-bearing sands in wells $A, B$ and $C$ vary from $0.34 \times 10^{-6} \mathrm{psi}^{-1}$ to $0.37 \times 10^{-6} \mathrm{psi}^{-1}$ (with an average value of $\left.0.36 \times 10^{-6} \mathrm{psi}^{-1}\right), 0.33 \times 10^{-6} \mathrm{psi}^{-1}$ to $0.36 \times$ $10^{-6} \mathrm{psi}^{-1}$ (with an average value of $0.34 \times 10^{-6} \mathrm{psi}^{-1}$ ), and $0.34 \times 10^{-6} \mathrm{psi}^{-1}$ to $0.40 \times 10^{-6} \mathrm{psi}^{-1}$ (with average value of $0.37 \times 10^{-6} \mathrm{psi}^{-1}$ ) respectively. These average values are less than the threshold, hence, the results of the computation suggest that the reservoir rock may be less prone to sanding and indicate high percentage of oil in the sand units in wells $A, B$ and $C$.

In well B, as presented in Table 3, average bulk compressibility for water-bearing sand, gas-bearing sand and gas-bearing shale are $0.51 \times 10^{-6} \mathrm{psi}^{-1}, 0.57 \times 10^{-6}$ $\mathrm{psi}^{-1}$ and $0.64 \times 10^{-6} \mathrm{psi}^{-1}$ respectively. While in well $\mathrm{C}$, as depicted in Table 4, average bulk compressibility for waterbearing sand, gas-bearing sand and gas-bearing shale are $0.37 \times 10^{-6} \mathrm{psi}^{-1}, 0.62 \times 10^{-6} \mathrm{psi}^{-1}$, and $0.59 \times 10^{-6} \mathrm{psi}^{-1}$ respectively. These average values are higher than what was obtained in oil-bearing sand units, but less than the threshold.

\subsection{Crossplot of heat production and Young's modulus}

The plots of heat production versus Young's modulus of reservoir sands 1,2, and 3 for each of the three wells (wells A, B, and C) are presented in Figs. 5, 6, 7 respectively. Table 5 shows the average heat production for wells $A, B$, and $C$ (oil-bearing sand). Well $C$ has the highest average heat production of $620.26 \mu \mathrm{W} / \mathrm{m}^{3}$, 

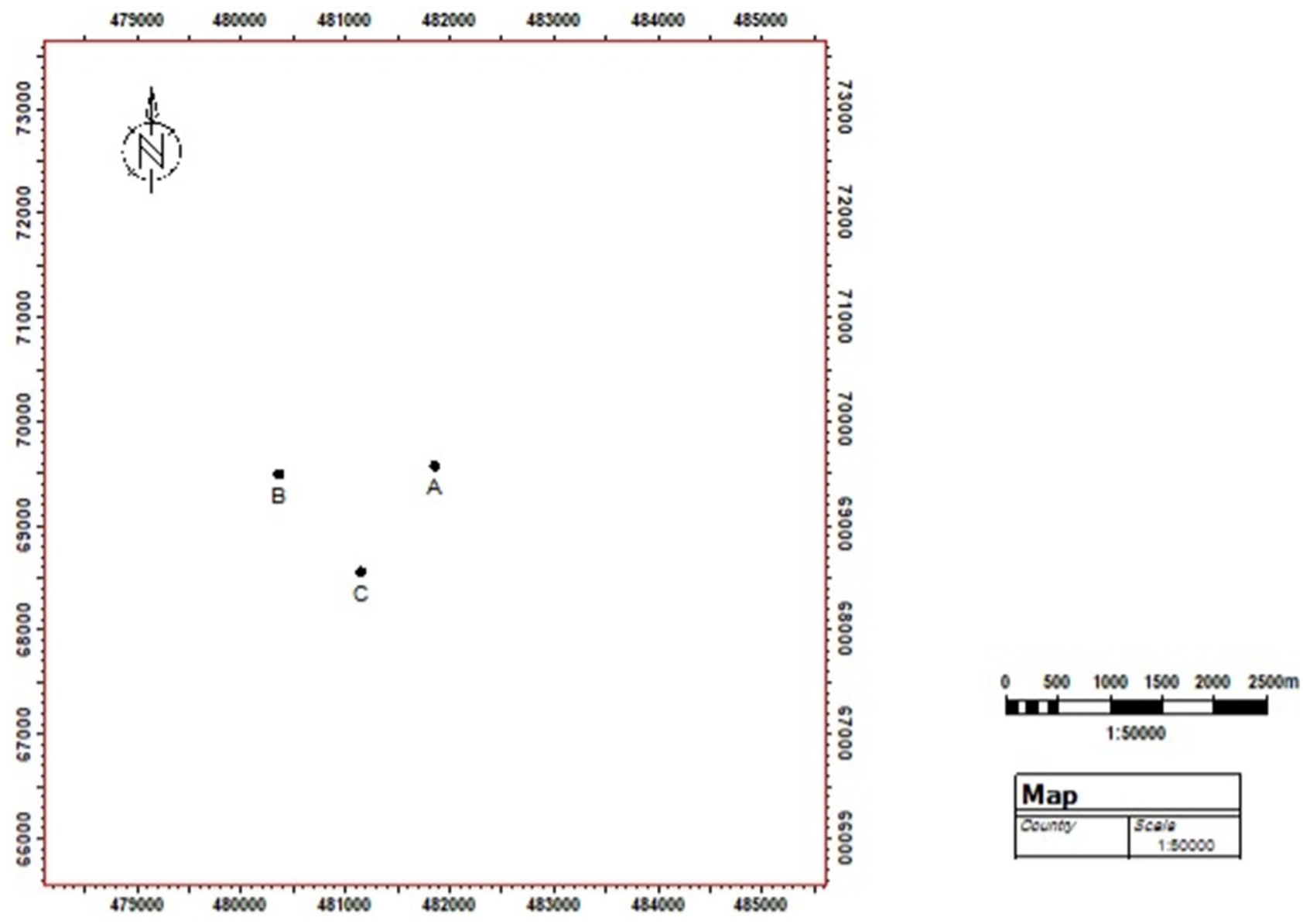

Fig. 4 Map of the study area showing well locations

Table 2 Average rock elastic properties for oil-bearing sands in wells $A, B$ and $C$

\begin{tabular}{lllllllll}
\hline Well & Sand & Depth (ft) & $\mathrm{U}$ & $\mathrm{G}(\mathrm{psi})$ & $\mathrm{E}(\mathrm{psi})$ & $\mathrm{K}_{\mathrm{b}}(\mathrm{psi})$ & $\mathrm{C}_{\mathrm{b}}\left(\mathrm{psi} \mathrm{i}^{-1}\right)$ & $\mathrm{SPI}\left(10^{7} \mathrm{Mpa}\right)$ \\
\hline $\mathrm{A}$ & Sand 1 & $8380.5-8667.5$ & 0.23 & 71.66 & 171.71 & 2.70 & 0.37 & 19.76 \\
& Sand 2 & $9139.5-9394.5$ & 0.23 & 77.15 & 160.20 & 2.71 & 0.37 & 23.32 \\
& Sand 3 & $9513.5-9997.5$ & 0.21 & 82.40 & 199.02 & 3.02 & 0.34 & 31.02 \\
$\mathrm{~B}$ & Sand 1 & $8398.0-8743.0$ & 0.23 & 74.74 & 180.96 & 2.82 & 0.36 & 21.24 \\
& Sand 2 & $9189.0-9541.0$ & 0.23 & 76.56 & 189.34 & 3.04 & 0.33 & 26.98 \\
& Sand 3 & $9628.0-10,013.5$ & 0.22 & 77.31 & 197.45 & 3.10 & 0.33 & 29.08 \\
$\mathrm{C}$ & Sand 1 & $8373.6-8645.8$ & 0.23 & 71.52 & 170.12 & 2.66 & 0.38 & 20.39 \\
& Sand 2 & $9249.3-9527.7$ & 0.24 & 73.70 & 187.14 & 2.64 & 0.40 & 20.15 \\
& Sand 3 & $9701.0-10,052.0$ & 0.20 & 86.01 & 197.91 & 2.96 & 0.34 & 28.58 \\
\hline
\end{tabular}

$\mathrm{U}=$ Poisson's Ratio, $\mathrm{G}=$ Shear Modulus, $\mathrm{E}=$ Dynamic Young's Modulus, $\mathrm{K}_{\mathrm{b}}=$ Bulk Modulus,

$\mathrm{C}_{\mathrm{b}}=$ Bulk Compressibility, $\mathrm{SPI}=$ Sand Production Index followed by well A $\left(590.22 \mu \mathrm{W} / \mathrm{m}^{3}\right)$ and well B has the lowest $\left(373.84 \mu \mathrm{W} / \mathrm{m}^{3}\right)$. The amount of heat produced by the shaly materials affects the elastic properties of the reservoir units and flow rate. The higher the amount of heat produced the greater the thermal agitation of the rock and this will lead to thermal expansion of the reservoir unit. The uneven thermal expansion of the grains may cause reduction of the pore space and pore throat which may affect the flow rate in terms of deceleration at the pore body and acceleration at the pore throat. Thus, effective porosity and permeability will be reduced. Materials with low thermal expansivity tend to crack or fracture when the elastic limit is exceeded. 
Table 3 Average elastic properties for gas-bearing sand and shale, and waterbearing sand in well $B$

Table 4 Average elastic properties for gas-bearing sand and shale, and waterbearing sand in Well $C$

\begin{tabular}{|c|c|c|c|c|c|c|c|}
\hline \multicolumn{8}{|l|}{ Well B } \\
\hline Lithology & Depth (ft) & u & G (psi) & $E$ (psi) & $\mathrm{K}_{\mathrm{b}}(\mathrm{psi})$ & $C_{b}\left(p s i^{-1}\right)$ & $\mathrm{SPI}\left(10^{7} \mathrm{Mpa}\right)$ \\
\hline Water-bearing sand & $5990-6020$ & 0.28 & 44.05 & 112.97 & 1.95 & 0.51 & 85.90 \\
\hline Gas-bearing sand & $4700-4820$ & 0.31 & 36.18 & 94.70 & 1.77 & 0.57 & 64.59 \\
\hline Gas-bearing shale & $4640-4695$ & 0.35 & 28.88 & 77.05 & 1.60 & 0.64 & 47.91 \\
\hline
\end{tabular}

$\mathrm{u}=$ Poisson's ratio, $\mathrm{G}=$ Shear Modulus, $\mathrm{E}=$ Dynamic Young's Modulus, $\mathrm{K}_{\mathrm{b}}=$ Bulk Modulus,

$\mathrm{C}_{\mathrm{b}}=$ Bulk Compressibility, SPI = Sand Production Index

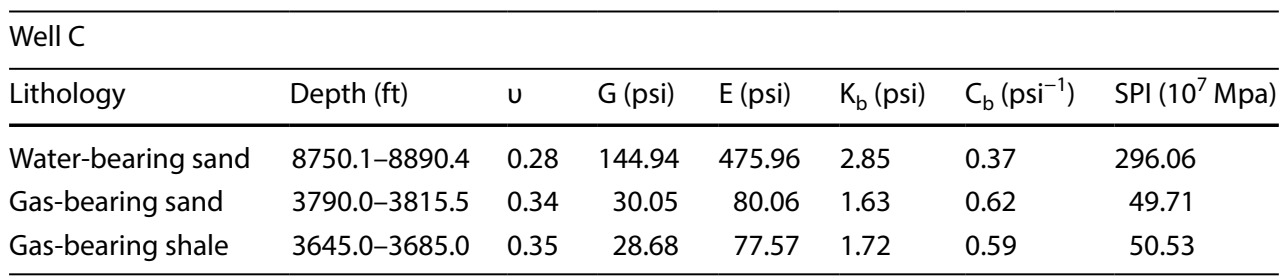

$\mathrm{U}=$ Poisson's ratio, $\mathrm{G}=$ Shear Modulus, $\mathrm{E}=$ Dynamic Young's Modulus, $\mathrm{K}_{\mathrm{b}}=$ Bulk Modulus,

$\mathrm{C}_{\mathrm{b}}=$ Bulk Compressibility, $\mathrm{SPI}=$ Sand Production Index
(A)

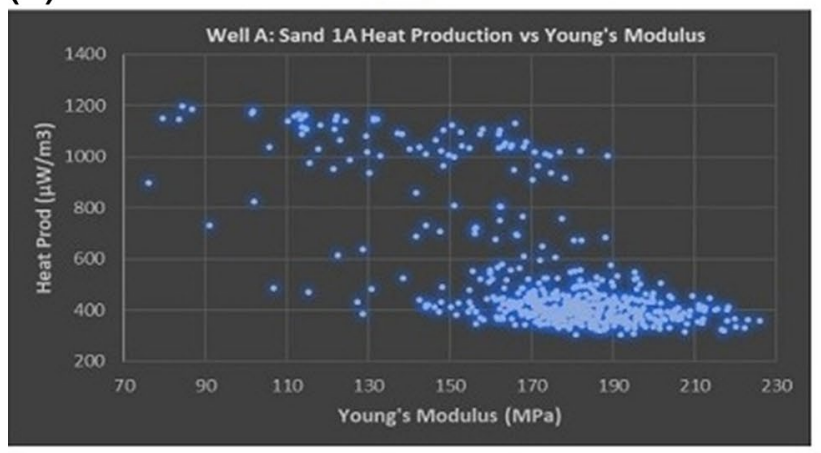

(B)

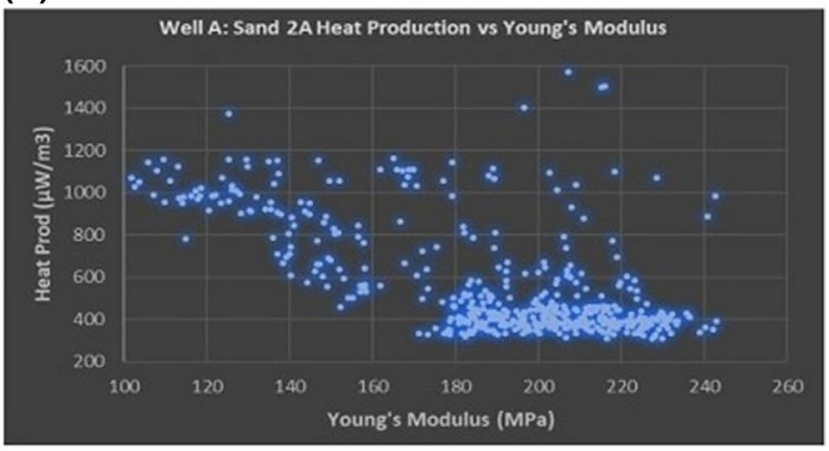

(C)

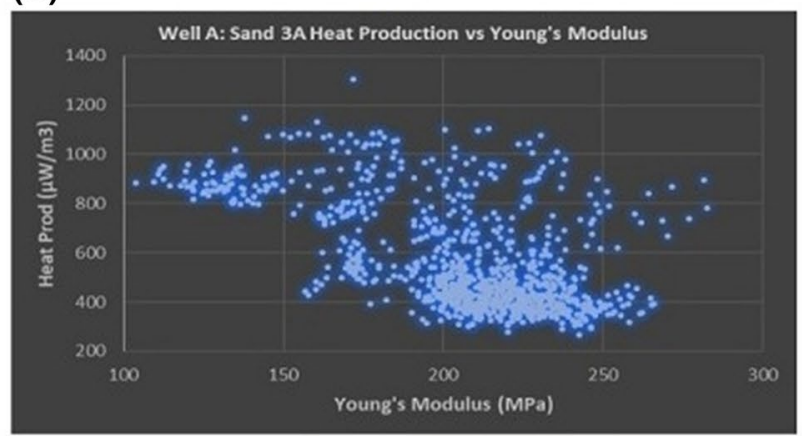

Fig. 5 Crossplot of heat production and Young's modulus in well A for [A] Sand 1, [B] Sand 2, and [C] Sand 3

Hence, it suggests that the reservoir rocks have relatively high Young's modulus and tend to be brittle. Average Young's modulus of the reservoir units for wells $A, B$ and $C$ are 176.98 psi, 198.25 psi and 185.06 psi respectively, indicating that the reservoir rock in well $B$ is relatively most brittle while that of well $A$ is least brittle.

\subsection{Crossplot of Poisson's ratio and compressional velocity}

Poisson's ratio $v$, is the ratio of lateral expansion to axial shortening. In $3 \mathrm{D}$, it is a rank-0 tensor having only one component. The plots of Poisson's ratio against compressional velocity of reservoir sands 1, 2, and 3 for each of 
(A)

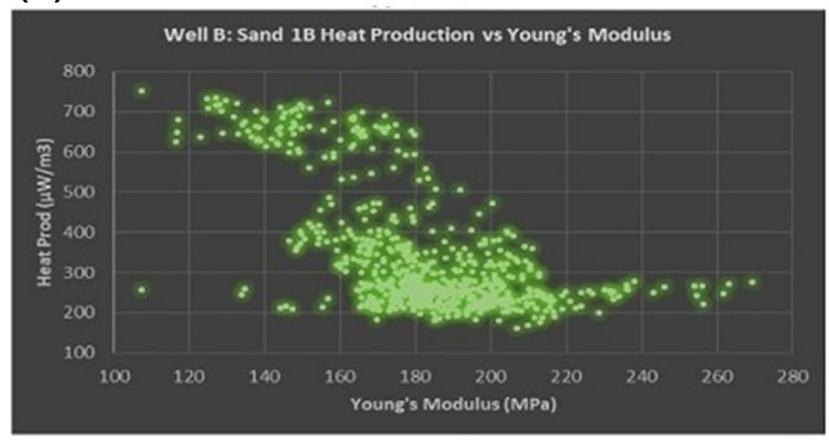

(B)

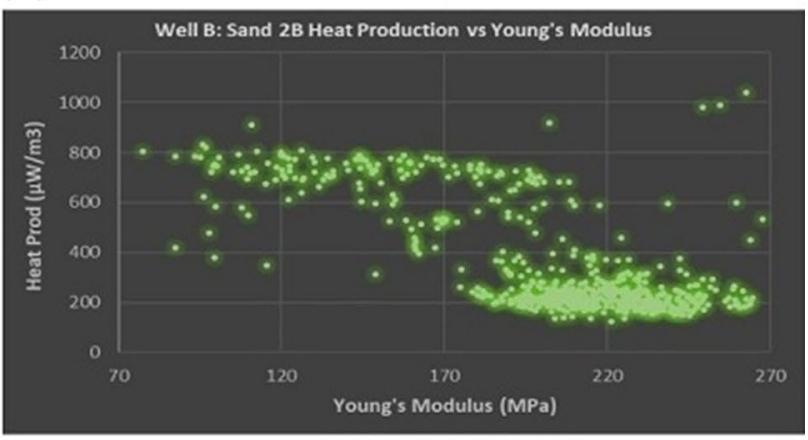

(C)

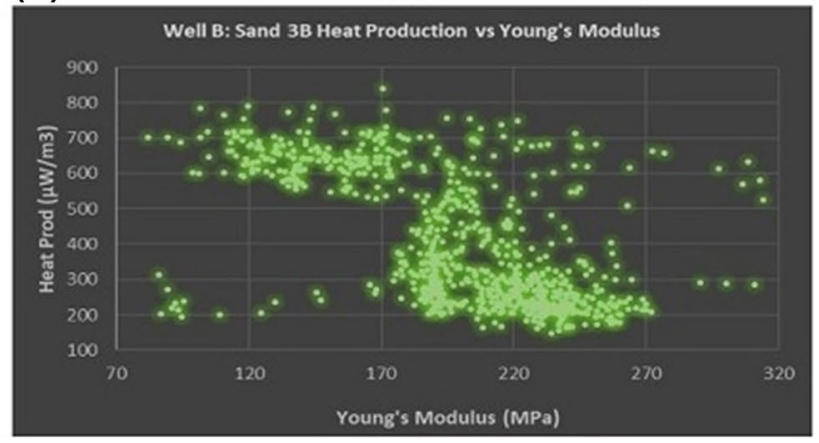

Fig. 6 Crossplot of heat production and Young's modulus in well B for [A] Sand 1, [B] Sand 2, and [C] Sand 3

(A)

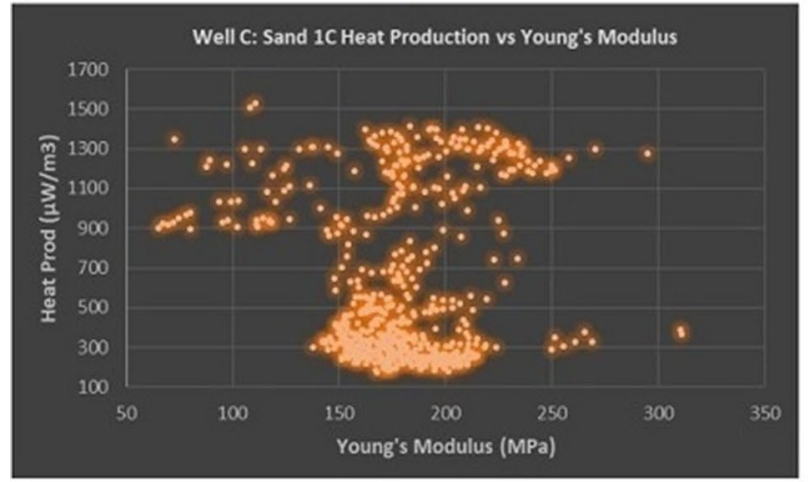

(B)

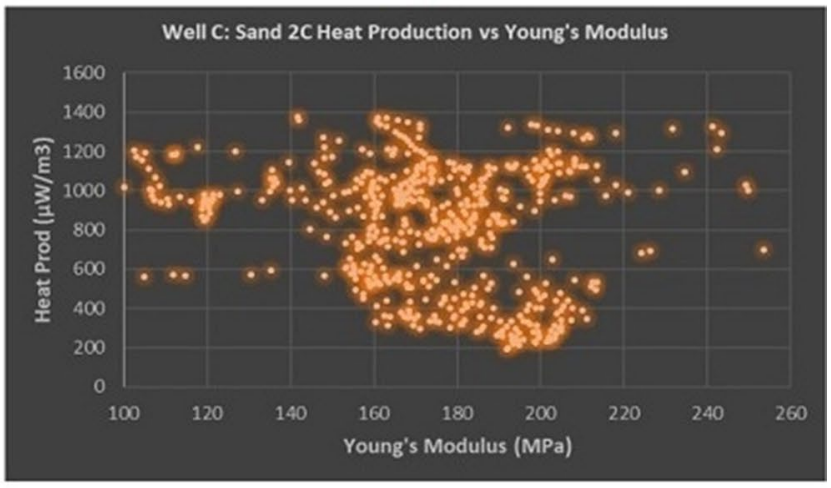

(C)

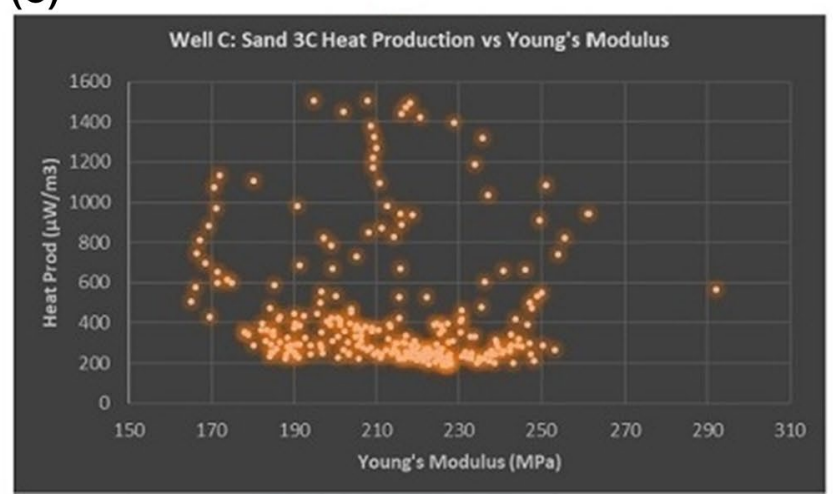

Fig. 7 Crossplot of heat production and Young's modulus in well C for [A] Sand 1, [B] Sand 2, and [C] Sand 3

\section{SN Applied Sciences}

a SPRINGer Nature journal 
Table 5 Average rock inelastic properties for wells A, B and C

\begin{tabular}{lllllllll}
\hline Well & Sand & Depth (ft) & UCS $(\mathrm{psi})$ & $\tau(\mathrm{Mpa})$ & $\mathrm{A}(\mu \mathrm{W} / \mathrm{m} 3)$ & $\mathrm{S}_{\mathrm{v}}(\mathrm{psi})$ & $\mathrm{S}_{\mathrm{Hmax}}(\mathrm{psi})$ & $\mathrm{S}_{\mathrm{hmin}}(\mathrm{psi})$ \\
\hline \multirow{2}{*}{ Well A } & Sand 1 & $8380.5-8667.5$ & $104,406.33$ & $59,306.37$ & 518.91 & $57,201.30$ & $17,236.71$ & $13,154.66$ \\
& Sand 2 & $9139.5-9394.5$ & $111,520.05$ & $71,214.87$ & 696.80 & $62,448.32$ & $18,193.73$ & $14,373.72$ \\
& Sand 3 & $9513.5-9997.5$ & $122,289.51$ & $83,561.68$ & 554.96 & $65,488.19$ & $17,651.70$ & $13,753.44$ \\
\multirow{2}{*}{ Well B } & Sand 1 & $8398.0-8743.0$ & $108,663.74$ & $66,222.96$ & 337.46 & $57,885.09$ & $16,975.26$ & $13,315.79$ \\
& Sand 2 & $9189.0-9541.0$ & $120,256.49$ & $83,277.13$ & 377.37 & $63,762.37$ & $18,840.57$ & $14,667.58$ \\
& Sand 3 & $9628.0-10,013.5$ & $117,330.55$ & $84,616.00$ & 406.69 & $66,499.07$ & $20,534.71$ & $15,297.01$ \\
\multirow{2}{*}{ Well C } & Sand 1 & $8373.6-8645.8$ & $104,636.93$ & $65,501.73$ & 526.60 & $57,958.79$ & $18,250.52$ & $13,332.75$ \\
& Sand 2 & $9249.3-9527.7$ & $177,948.69$ & $63,154.61$ & 833.29 & $64,016.77$ & $21,265.88$ & $15,366.27$ \\
& Sand 3 & $9701.0-10,052.0$ & $127,083.75$ & $73,984.87$ & 500.88 & $66,505.69$ & $16,239.56$ & $13,303.35$ \\
\hline
\end{tabular}

the three wells (wells $A, B$, and $C$ ) as shown in Figs. 8, 9, 10 respectively, indicate the effect of lithology and gas. A high Poisson's ratio is an indication of high stress level, which is characterized by probable boundaries of hydraulic fracture. Low value of Poisson's ratio indicates an evidence of

(A)

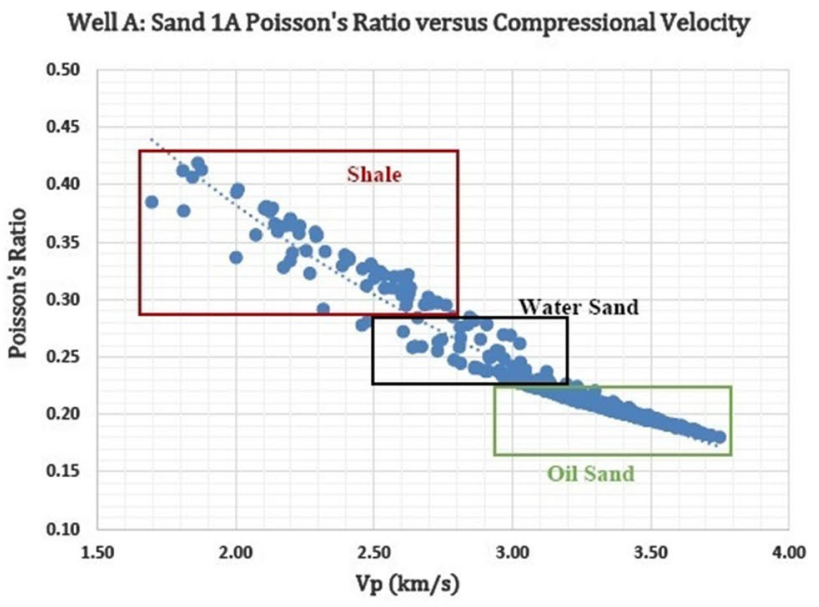

weak zones and may not constrain the fracturing process but as a result of communication to undesired formations. Also, permeable sandstone have compressional velocity ranging from 2.5 to $4.5 \mathrm{~km} / \mathrm{s}$ [23]. Therefore, the oil-bearing sand units show relatively low average Poisson's ratio

(B)

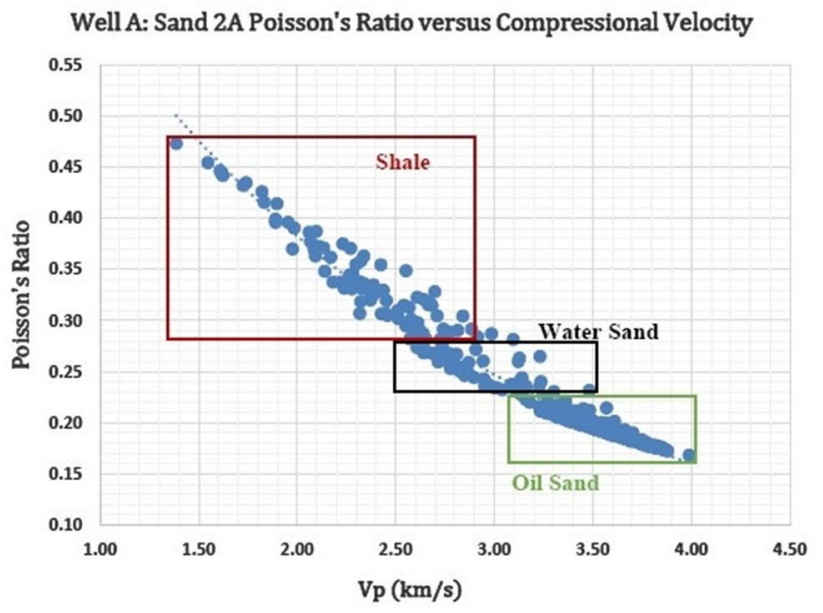

(C)

Well A: Sand 3A Poisson's Ratio versus Compressional Velocity

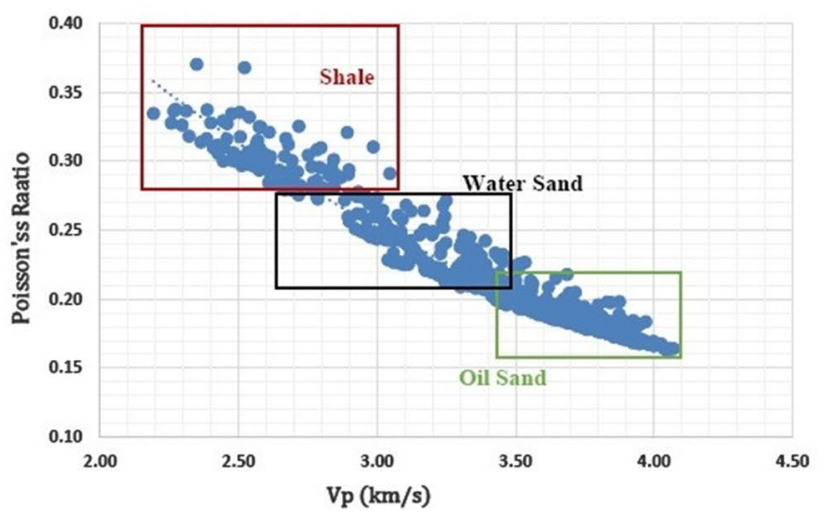

Fig. 8 Crossplot of Poisson's ratio and compressional velocity in well A for [A] Sand 1, [B] Sand 2, and [C] Sand 3 
(A)

Well B: Sand 1B Poisson's Ratio versus Compressional Velocity

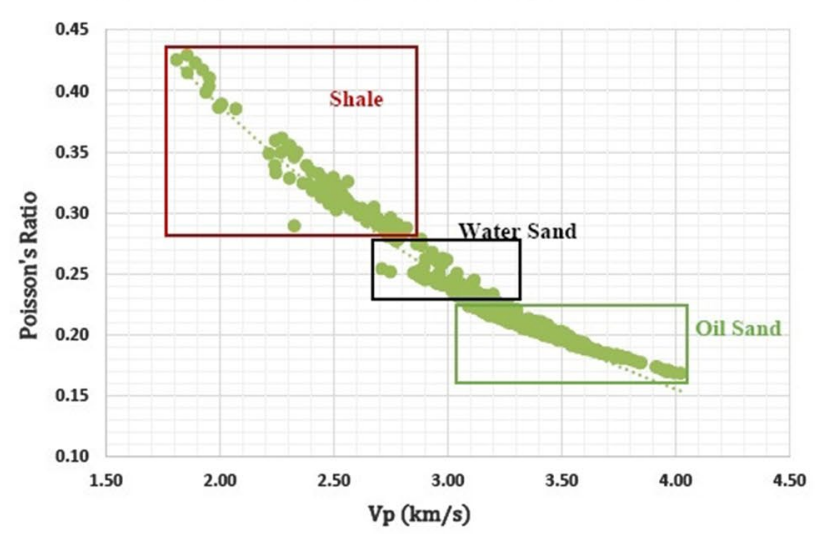

(B)

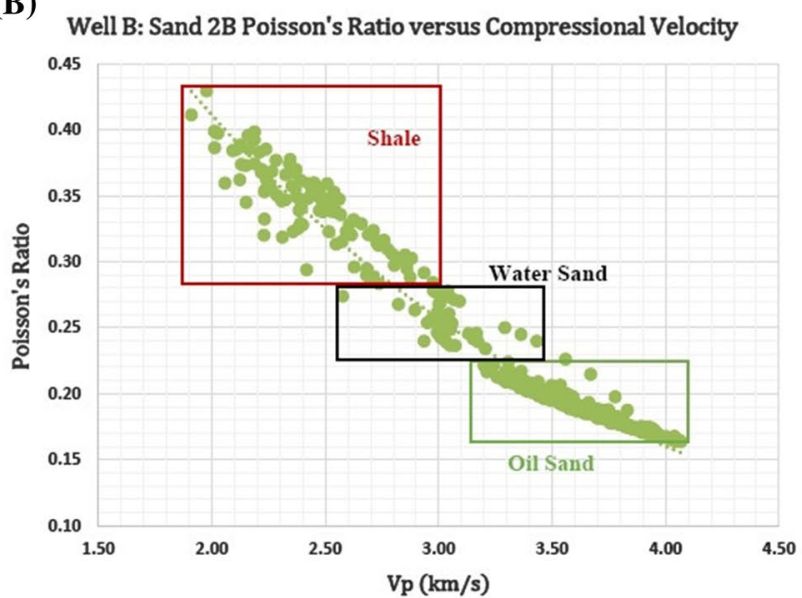

(C)

Well B: Sand 3B Poisson's Ratio versus Compressional Velocity

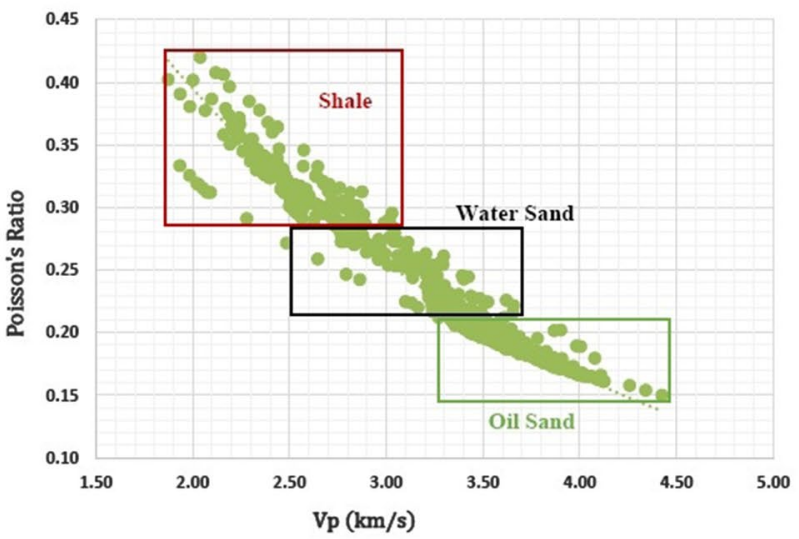

Fig. 9 Crossplot of Poisson's ratio and compressional velocity in well B for [A] Sand 1, [B] Sand 2, and [C] Sand 3

(0.22) while higher Poisson's ratio (greater than 0.28) is indicative of shale units and the values of Poisson's ratio in between 0.22 and 0.28 which result from the presence of other types of saturating fluids such as water. From the plots of the Poisson's ratio versus compressional velocity, the crossplots are expressly well-defined and exponentially decaying with compressional velocity, indicating an inverse relationship between the Poisson's ratio and compressional velocity.

\subsection{Reservoir rock strength and stresses}

The result of the stress tensor analysis shows that the vertical stress (overburden) is greater than the maximum horizontal stress and the maximum horizontal stress greater than the minimum horizontal stress in each reservoir unit, that is, $\mathbf{S}_{\mathbf{v}}>\mathbf{S}_{\mathrm{H} \text { max }}>\mathbf{S}_{\text {hmin. }}$.

The stress tensors for sands in wells $A, B$ and $C$ are as follow;

$$
\begin{aligned}
& \mathbf{S}^{\mathbf{A} \text { oil sand }}=\left[\begin{array}{ccc}
61712.62 & 0 & 0 \\
0 & 17693.90 & 0 \\
0 & 0 & 13760.61
\end{array}\right] \text { psi } \\
& \mathbf{S}^{\mathbf{B} \text { oil sand }}=\left[\begin{array}{ccc}
62715.00 & 0 & 0 \\
0 & 18783.51 & 0 \\
0 & 0 & 14426.79
\end{array}\right] \text { psi } \\
& \mathbf{S}^{\text {C oil sand }}=\left[\begin{array}{ccc}
62827.05 & 0 & 0 \\
0 & 18585.32 & 0 \\
0 & 0 & 14000.79
\end{array}\right] \text { psi }
\end{aligned}
$$

The overburden is less than the UCS of the rock. Therefore, the required value of the least principal stress $\left(\sigma_{3}\right)$ would actually be tensile. Hence, the minimum horizontal stress $\mathbf{S}_{\text {hmin }}$ will be small in regions where normal faulting occurs and this is evident in the 
(A)

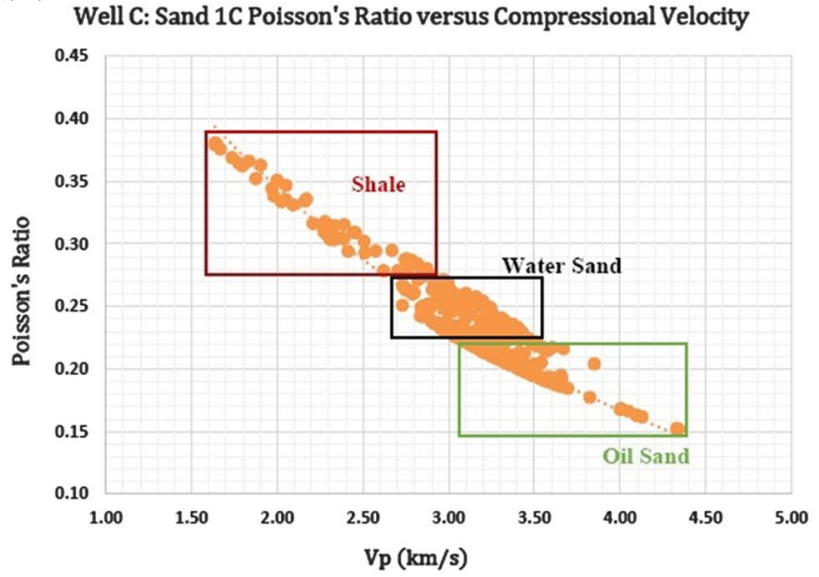

(B)

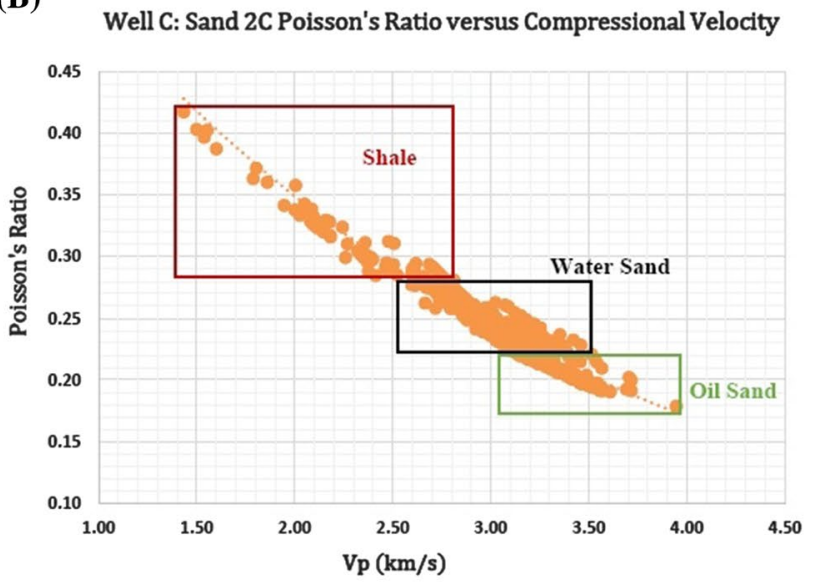

(C)

Well C: Sand 3C Poisson's Ratio versus Compressional Velocity

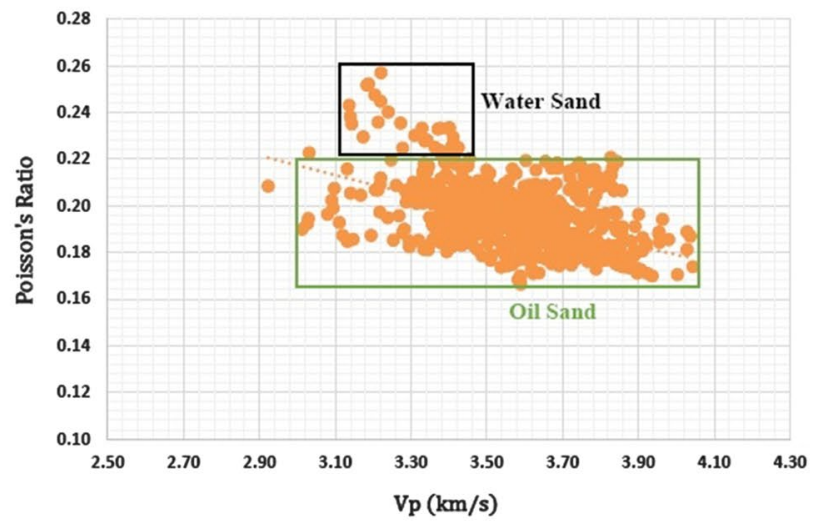

Fig. 10 Crossplot of Poisson's ratio and compressional velocity in well C for $[A]$ sand 1, $[B]$ sand 2, and $[C]$ sand 3

result of stress analysis carried out. In a normal fault region, $\mathbf{S}_{\mathbf{v}}>\mathbf{S}_{\mathrm{Hmax}}>\mathbf{S}_{\mathrm{hmin}^{\prime}}$ of which vertical stress dominates, thus greatest principal stress $\left(\boldsymbol{\sigma}_{\mathbf{1}}\right)$ equal to $\mathbf{S}_{\mathbf{v}}$. If the strength of the rock is higher than the vertical stress acting on it, there will be little or no lateral deformation of the rock. Across the three wells and in each sand unit, average UCS is greater than the shear strength and the vertical stress.

This implies that either the strength of the reservoir rock is high or the pore pressure of the reservoir rock is high enough to withstand the vertical stress. Both UCS and vertical stress increase down the wellbore as shown in Fig. 11. These observations suggest that low rock strength may account for the occurrence of wellbore failures in shales and shaly sandstone units. The type of fault regime prevalent in the study area was determined in line with the defining condition $\left(\mathbf{S}_{\mathbf{v}}>\mathbf{S}_{\mathrm{Hmax}}>\mathbf{S}_{\mathbf{h m i n}}\right)$ for Andersen's classification of the fault in the region as normal fault [24]. This extensional regime implies that the pore pressure is close to the hydrostatic pressure for the least principal stress to be significantly below the $\mathbf{S}_{\mathbf{v}}$.

\subsection{Projection of stress vector on the fault plane}

The principal stresses obtained are the eigenvalues and the projection of the stresses onto the fault plane is the dot product operations of the stress tensor on the eigenvector. The unit vector normal to the fault plane $(\hat{n})$, unit vector in the direction of $\operatorname{dip}\left(\hat{n}_{d}\right)$ and unit vector in the direction of strike $\left(\hat{n}_{s}\right)$ were determined and the results are as follow:

$\hat{n}=\left[\begin{array}{c}-0.6124 \\ 0.6124 \\ -0.5\end{array}\right]$ 

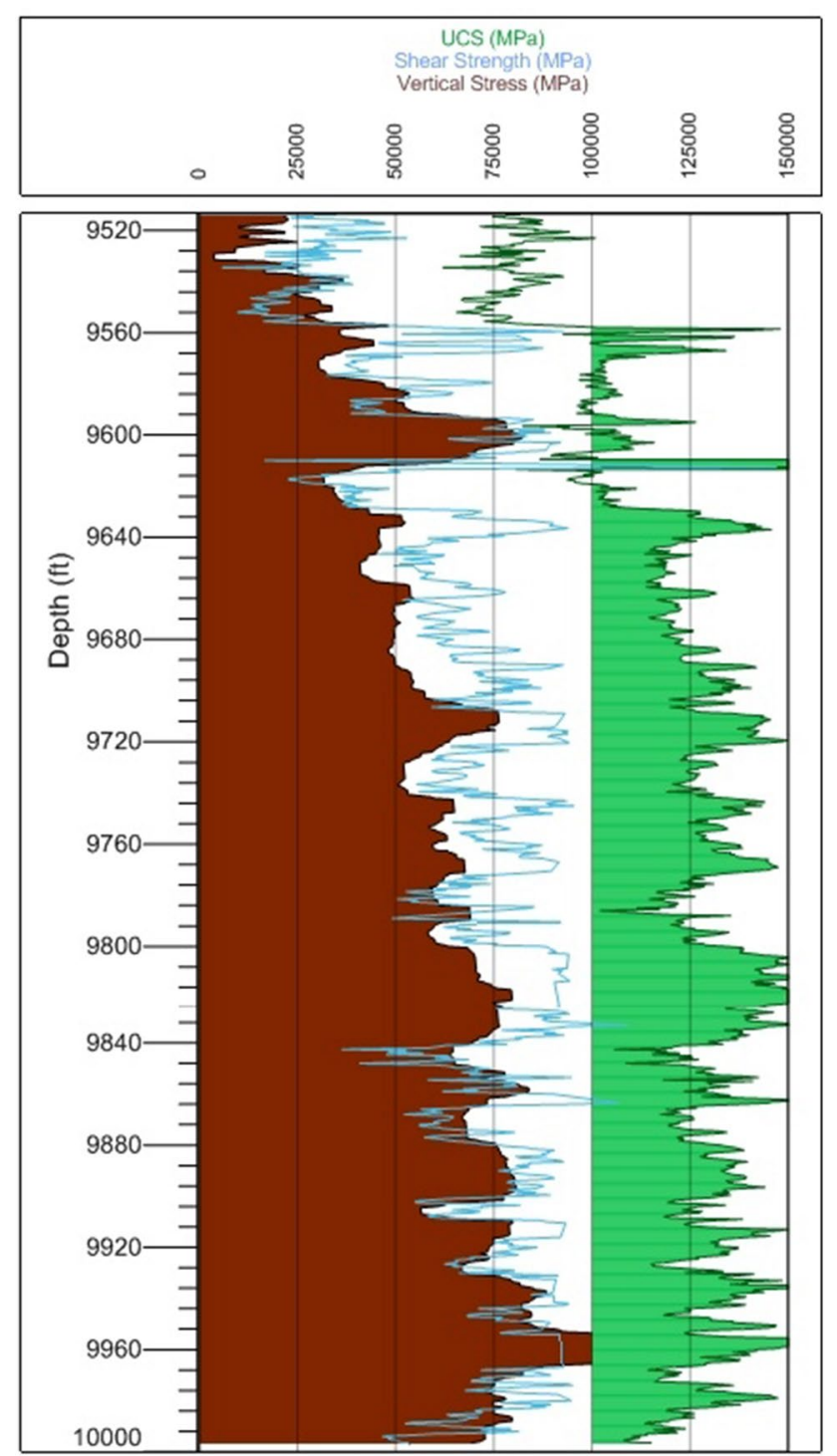

Fig. 11 Plot of unconfined compressive strength (UCS), shear strength $(\tau)$ and vertical stress $\left(\mathrm{S}_{\mathrm{v}}\right)$ against depth

$$
\begin{gathered}
\hat{n}_{d}=\left[\begin{array}{c}
-0.3536 \\
0.3536 \\
0.8660
\end{array}\right] \\
\hat{n}_{s}=\left[\begin{array}{c}
0.7071 \\
0.7071 \\
0
\end{array}\right]
\end{gathered}
$$

Similarly, a dot product operation was done to estimate the orientation of the principal stresses on the fault plane and the results are presented in Table 6 . From the computation, the stress in the normal direction of the fault plane
Table 6 Projection of stress vector on the fault plane (fault orientation) for wells $A, B$ and $C$

\begin{tabular}{llrl}
\hline Wells & $\mathrm{S}_{\mathrm{n}}$ (psi) & \multicolumn{1}{c}{$\tau_{d}$ (psi) } & \multicolumn{1}{l}{$\tau_{s}(\mathrm{psi})$} \\
\hline Well A & $30,770.70$ & 9822.32 & $-16,232.92$ \\
Well B & $34,171.39$ & $11,401.26$ & $-19,023.57$ \\
Well C & $34,002.59$ & $11,549.74$ & $-19,192.55$ \\
\hline
\end{tabular}

$\mathrm{S}_{\mathrm{n}}=$ Stress in the normal direction of the fault plane, $\tau_{d}=$ Shear stress in the direction of the dip and $\tau_{s}=$ Shear stress in the direction of the strike

ranges from $30,770.70$ psi to $34,171.39 \mathrm{psi}$, the shear stress in the direction of dip varies between 9,822.32 psi and $11,549.74 \mathrm{psi}$ and the shear stress in direction of the strike ranges from $-19,192.55$ psi to $-16,232.92$ psi. The negative shear stress in the direction of the strike indicates that the shear is in opposite direction to the strike direction of the fault plane.

Figure 12 shows a model of fault traction and principal stresses projected on the fault plane of the normal fault encountered in the study area. The strike and dip are measured from the north corresponding to the geographical coordinate system of the stress tensors.

\section{Conclusion}

We carried out a comprehensive estimation of several geomechanical parameters of selected reservoirs across three (3) different wells, A, B, and C, in "Tobi" Field, Niger Delta. Such parameters included Poisson's ratio, Young's modulus, shear modulus, bulk compressibility, sand production index (SPI), unconfined compressive strength (UCS), shear stress, heat production, vertical stress, maximum horizontal stress, minimum horizontal stress, stress normal to the fault plane, shear stresses in directions of strike and dip. It was observed that the field consists of reservoir units that have high UCS, low Poisson's ratio, low bulk compressibility, high Young's modulus and high SPI, which implied that the reservoir units may be less prone to sanding. High Young's modulus in oil-bearing reservoir rocks indicated brittle deformation. The oil-bearing sand units were characterized by relatively low Poisson's ratio (about 0.22). Stress tensor analysis, $S_{v}>S_{H \max }>S_{h \min }$ indicated that normal fault is prevalent in the study area. The shale units produced heat which affected the strength and stability of the wellbore. Therefore, estimation of geomechanical parameters is effective for reservoir characterization. 


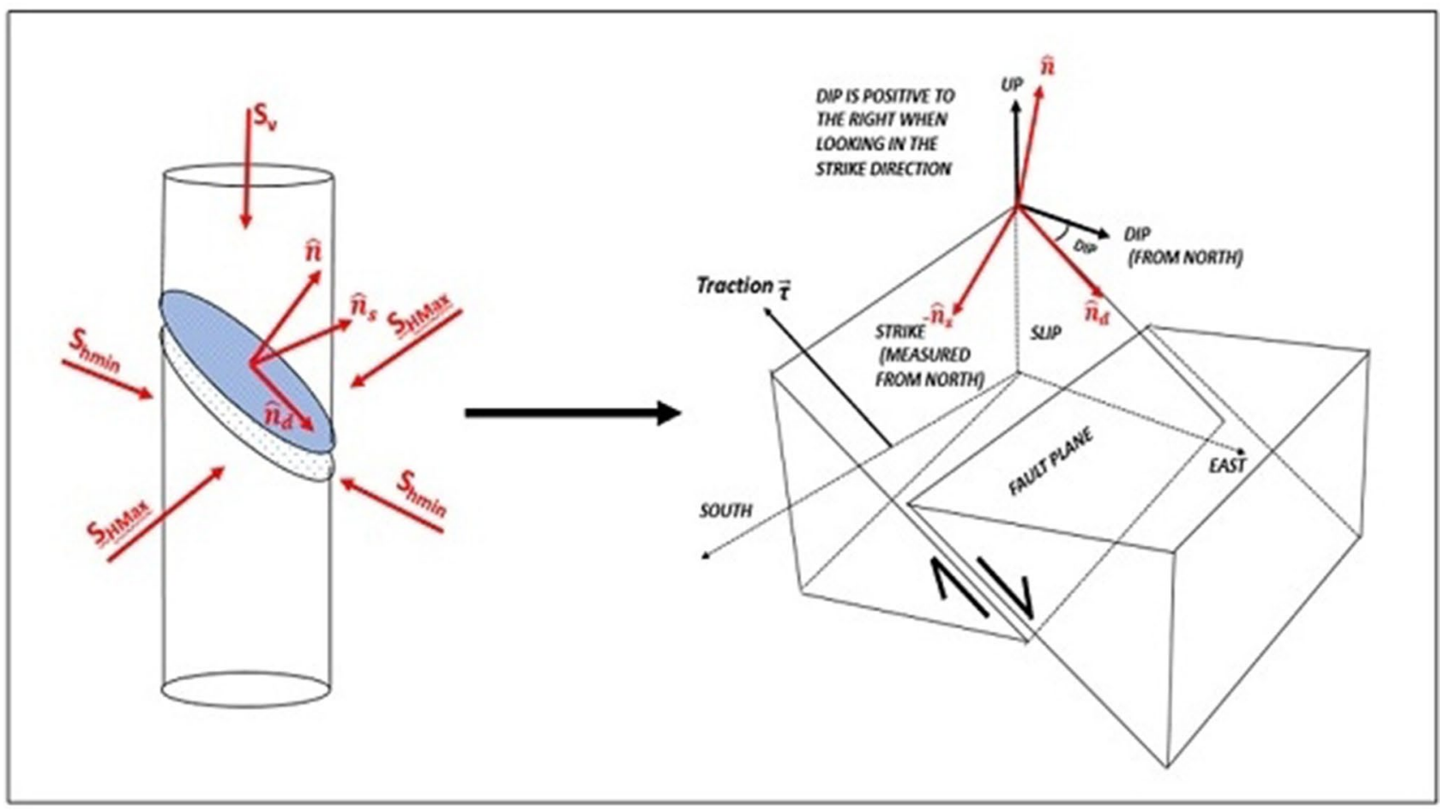

Fig. 12 Model of fault traction and principal stresses projected on the fault plane of the normal fault encountered in the study area

Funding Not applicable.

Data Availability Not applicable.

Code availability Not applicable.

\section{Compliance with ethical standards}

Conflict of interest On behalf of all authors, the corresponding author states that there is no conflict of interest.

\section{References}

1. Fjaer E, Holt RM, Raaen AM, Horsrud P (2008) Petroleum related rock mechanics, second edition. Developments in petroleum science, vol. 53. Elsevier Science, Elsevier. ISBN: 9780080557090

2. Qobi L (2016) What is geomechanics? Practical geomechanics: advisory, training and consultancy. https://www.practicalg eomechanics.com/blog/waht-is-geomechanics/. Accessed 28 November 2018

3. Dong $M$, Long $B$, Lun $L$, Juncheng $H$ (2013) Application of logging data in predicting sand production in oilfield. EJGE 18:6173-6180

4. Herwanger J, Koutsabeloulis N (2011) Seismic geomechanics: how to build and calibrate geomechanical models using 3D and 4D seismic data. EAGE Publication, Netherlands
5. Otti PE, Wood JD (2005) World oil: modern sand face completion practices handbook. Gulf Publishing Company, Houston, Texas

6. Oluyemi GF (2007) Intelligent grain size profiling using neural network and application to sand potential prediction in real time. PhD Thesis. Robert Gordon University, Aberdeen

7. Zoback M (2007) Reservoir geomechanics. Cambridge University Press, New York. https://doi.org/10.1017/CBO9780511586477. ISBN: 9780511586477

8. Avbovbo AA (1978) Geothermal gradients in the southern Nigeria Basin. Bull Can Petrol Geol 26(2):268-274

9. Doust H, Omatsola E (1990) Niger Delta. In J.D. Edwards and P. A. Santogossi (Eds.), Divergent/Passive Margin Basins. AAPG [American Association of Petroleum Geologists] Bulletin Memoir 48:239-248

10. Azizi V, Memarian H (2006) Estimation of geomechanical parameter of reservoir rocks, using conventional porosity log. In: Proceedings of 4th Asian rock mechanics symposium, rock mechanics in underground construction. https://doi. org/10.3997/2214-4609.201404063

11. Haftan M, Bohloli B, Eliassi M, Talebi B (2008) In-situ stress determination in sabalan geothermal reservoir. In: 2nd LASME/ WWSEAS international conference on geology and seismology (GES'08) Cambridge, UK, 23-25 February 2008, pp 88-93

12. Eshkalak MO, Mohaghegh SD, Esmaila S (2014) Geomechanical properties of unconventional shale reservoir. J Petrol Eng. https ://doi.org/10.1155/2014/961641

13. Harelen G, Nygaard R (2007) Calculating unconfined rock strength from drilling data. In: Proceedings of 1st CanadaUnited States rock mechanical symposium, Vancouver, British Columbia, Canada, 27-31 May 2007, pp 34-41

14. Haug K, Nygaard R, Keith V (2007) Evaluation of stress and geomechanical characteristics of a potential site for $\mathrm{CO}_{2}$ 
geological storage in Central Alberta, Canada. Breaking grounds in the nation's capital. Diamond Jubilee Ottawa Paper 2007, pp $1-8$

15. Eyinla DS, Oladunjoye MA (2014) Estimating geo-mechanical strength of reservoir rocks from well logs for safety limits in sand-free production. J Environ Earth Sci 4(20):38-43

16. Greenberge ML, Castagna JP (1992) Shear wave velocity estimation in porous rocks. Theoretical formulations: preliminary verification and application. Geophys Prospect 40(2):195-209. https://doi.org/10.1111/j.1365-2478.1992.tb00371.x

17. Ramsay JG, Lisle R (2000) The techniques of modern structural geology: applications of continuum mechanics in structural geology, 3rd edn. Academic Press, pp 702-1061. ISBN: 0125769237

18. Crain ER (1999) Crain's petrophysical handbook. https://www. spec2000.net. Accessed 20 December 2018

19. Bucker C, Ryback $L$ (1996) A simple method to determine heat production from gamma-ray logs. Mar Pet Geol 13:373-375

20. Jaeger J, Cook NG, Zimmerman R (2007) Fundamentals of rock mechanics, Fourth Edition. Blackwell Publishing Limited. ISBN 0632057599
21. Bhawani S, Goel RK (2006) Tunnelling in weak rocks, volume 5, 1st edn. In: Elsevier Geo-Engineering Book Series. Elsevier Science, Elsevier, Amsterdam

22. Taha $S$ (2016) Introduction to tensor calculus. arXiv:1603.01660v3 [math.HO] 23/25 May 2016

23. Yang S (2017) Fundamentals of petrophysics, 2nd edn. Springer Nature and jointly published with Petroleum Industry Press, Beijing, China, Springer Geophysics

24. Anderson EM (1951) The dynamics of faulting and dyke formation with applications to Britain Edinburgh, UK, 2nd edn. Oliver and Boyd, Edinburgh

Publisher's Note Springer Nature remains neutral with regard to jurisdictional claims in published maps and institutional affiliations. 